\title{
Automatic environmental quality assessment for mixed-land zones using lidar and intelligent techniques
}

\author{
Jorge Garcia-Gutierrez, Luis Gonçalves-Seco, Jose C. Riquelme-Santos
}

Keywords:

Intelligent techniques

Classification

Decision trees

Lidar

Land uses

Land cover

LULC
A B S T R A C T

\section{Introduction}

The coast of Huelva, in the south of Spain, is a clear example of industrial progression and environmental protection coexisting in a common space. In proximity to the capital, a great number of industrial areas exist including the refineries that feed fuel to the southern area of Spain as well as coastal areas with high touristic development. The combination of both factors puts large natural areas at risk such as the Doñana National Park, within which can be found endangered species such as the Iberian Lynx (lynx pardi$n u s$ ), in great risk of extinction. The human impact on this and other areas of the territory concerns the Regional Ministry for the Environment of Andalusia which is designating large quantities of resources to control it.

The human influence on natural surroundings is not only a local fact. Many authors recognize that human beings and their activities are the principle factor that influences the evolution of the natural environment. In addition, human impact is a key factor when planning protection policies for natural spaces. Two key factors that are often studied to detect human activity are transport networks and urban nuclei (Goetz, Jantz, \& Jantz, 2009; Svancara, Scott, Loveland, \& Pidgorna, 2009). These parameters permit evaluating the risk of damage to natural areas nearby (Jones et al., 2009) and to draw up policies to correct the possible effects of human development. One of the most important tools to control these factors is the control and monitoring of land uses and land cover (LULC) using remote sensing.

Since its appearance, remote sensing has been used with different purposes in terms of natural resources. Recently, many authors have used remote sensing to monitor species (Stow, Hamada, Coulter, \& Anguelova, 2008), or changes in cities (Gamanya, Maeyer, \& Dapper, 2009), characterize the morphology of urban nuclei (Gill et al., 2008), study the richness of bird species in natural areas (Goetz, Steinberg, Dubayah, \& Blair, 2007) or the severity of fires (Kokaly, Rockwell, Haire, \& King, 2007), etc. In terms of monitoring changes, the authors mainly tend to use classical remote sensing techniques based on satellite images (Fraser, Olthof, \& Pouliot, 2009; Pignatti et al., 2009; Townsend, Lookingbill, Kingdon, \& Gardner, 2009). It is important to bear in mind that studies of monitoring changes in natural environments are based on the interpretation of LULC maps (Svancara et al., 2009; Wang et al., 2009). In this way, an advance in the generation of these products will imply a possible direct improvement of the results obtained with these methodologies. Furthermore to the monitoring of changes, LULC has been studied profusely (Schubert, Sanders, Smith, \& Wright, 2008, 2009) with the general objective of treating areas of particular interest from an economical or environmental point of view. In these cases, planning and management 
play an important role at the time of exploiting the resources but are always subject to the quality of the products extracted from remote sensing (Dorigo et al., 2007; Kennedy et al., 2009).

The new technologies based on novel sensors, such as lidar, have become an excellent tool for improving the results of traditional remote sensing (Chen, 2007). Its capacity to register the height of objects overcomes the limitations that usually come with working with images. Due to this ability, it is relatively simple to distinguish between the ground and objects to develop digital terrain models (DTM), a primary product for a wide variety of applications. To produce DTM's, a multitude of techniques have been proposed from the lidar point cloud (Evans \& Hudak, 2007; Sithole \& Vosselman, 2003). It is very important to point out that the laser is not affected by shadows and their associated problems nor does it need to be flown during the day due to its special characteristics. All these advantages, along with a progressive decrease in the related costs compared to other data sources such as satellite images, make lidar one of the leading technologies in environmental investigation.

In accordance with the proven usefulness of lidar, many investigators have chosen to use it as supporting technology for images. In this way, they tend to fuse sensors, with the objective of improving the results obtained separately (Arroyo, Pascual, \& Manzanera, 2008; Bork \& Su, 2007; Chust, Galparsoro, Franco, \& Uriarte, 2008; Dalponte, Bruzzone, \& Gianelle, 2008) whilst others focus their efforts on lidar as the only data source with excellent results (Chen, Su, Li, \& Sun, 2009; Pascual, Garcia-Abril, Garcia-Montero, MartinFernandez, \& Cohen, 2008). Each strategy has its own advantages and disadvantages. The fusion provides a large quantity of data that produces extra information for any classification method. But also, it requires greater effort to adapt data from multiple sensors giving place to an increase in development and testing time. Furthermore, some studies show little improvement in classifications based on fusion among lidar and other sensors when they are used to carry out determined tasks (Jensen, Humes, Vierling, \& Hudak, 2008; Thessler et al., 2008). Other works (Townsend et al., 2009) advise being cautious when merging data in general, including if they are of the same typology which could be the case with satellite images.

Another important decision to bear in mind is the work paradigm selection. In classical remote sensing, the smallest significant unit is the pixel which is characterized by having a standard size. The data sources are divided in one series of pixels from which information is extracted to be used later for general classification. Instead, recently, a new paradigm of work has started to be applied, object-oriented approaches (Gamanya, Maeyer, \& Dapper, 2007). An object, contrary to a pixel, does not have a fixed size but depends on the type of the object in question. Thus, the data to classify is decomposed in diverse objects of variable size which have been extracted through some type of segmentation technique at a previous stage. Lately, the application of object-oriented techniques has commenced on lidar as a unique data source to resolve various tasks with good results (Antonarakis, Richards, \& Brasington, 2008; Donoghue, Watt, Cox, \& Wilson, 2007). In this case, the object-oriented techniques apply a segmentation from computer vision techniques using a set of features extracted from lidar. Afterwards, the classification method proceeds to learn from the segmented objects to classify future instances. Despite the results being very promising, unresolved problems still exist, essentially because segmentation of lidar data is not a process easily automated needing the interaction with the user to achieve good results. An additional problem is that the return intensity is one of the main parameters used in carrying out segmentation with lidar. This datum can be affected by other factors (impact angle, sensor distance (Hofle \& Pfeifer, 2007) which can modify its value and falsify the final result. As opposed to object orientation, the traditional pixel-based approaches and work with models resulting of the application of advanced intelligent techniques (Witten \& Frank,
2005) could be applied on lidar with good results and with much greater levels of automation. In this sense, numerous studies show that intelligent techniques could be applied to lidar data, such as vector-support machines (Koetz, Morsdorf, van der Linden, Curt, \& Allgower, 2008), artificial neural networks (Brzank, Heipke, Goepfert, \& Segel, 2008) or clustering (Pascual et al., 2008).

In this work we show a new application of intelligent techniques with the objective of extracting hidden knowledge in lidar data and use it to work on urban and natural areas with the objective of:

- Defining a general method based on intelligent techniques to classify high resolution LULC using lidar as a unique data source and to demonstrate its value to detect human activity in an automated manner.

- Using this method to evaluate the human impact on a riparian area located on the Atlantic coast of Huelva province (Andalusia, Spain) close to the Doñana National Park.

\section{Data description}

The data for this work was provided by REDIAM (Andalusia Environment Information Network) which pertains to the Regional Ministry for the Environment of Andalusia. The data was taken in coastal areas of the province of Huelva (see Fig. 1) and Cadiz between the 23rd and 25th of September 2007 and the flight was operated at an average height of $1200 \mathrm{~m}$ with low inclination angles $\left(<11^{\circ}\right)$ and nominal density of 2 pulses $/ \mathrm{m}^{2}$. The pulses were geo-referenced and correctly validated by the distributor of the data and having 1,384,875 records. The reported precision indicates a maximum error of $0.5 \mathrm{~m}$ in the $x-y$ positions, and of $0.15 \mathrm{~m}$ in the $z$-position. As well, the rest of the LAS standard is available: intensity, angle, etc. Along with the lidar flight, aerial photographs were taken of the area and they were used in the training and testing selection phases.

The study area is located in the south of Spain, in the mouth of the Tinto and Odiel rivers (UTM30; 150960E 4124465N). Near the city of Huelva, this area presents a mix of land uses among which are found industrial areas, roads and railways, port facilities and natural areas. The vegetation can be divided in three large groups. The first being tall vegetation which is formed by scarce trees of the genus eucalyptus in the area. The middle vegetation would be formed by different types of Mediterranean bushes that principally surround roads and urban areas. Pastures are classified as low vegetation. Furthermore, the undeveloped land formed by marshland close to the river is another important class which must be taken into account in this ecosystem.

Lidar data can be exploited mainly depending on three factors: density, intensity and height. A brief study of the different responses of each terrain type could be useful to outline the main differences between each of the classes.

\subsection{Water}

The non-bathymetric lidar sensor does not usually reflect itself on underwater areas. This means that pixels classified as water will have low density. Furthermore, the few that do reflect will have low energy due to the large amount it refracts and loses. Finally, the differences among heights will be rare given that river mouths generally have gentle swells.

\subsection{Marshland}

Marsh areas are transitions between underwater terrain and vegetated or urban terrain. They are formed by low bush and different types of grass. It is characterized by low heights and medium/high intensity distribution. 


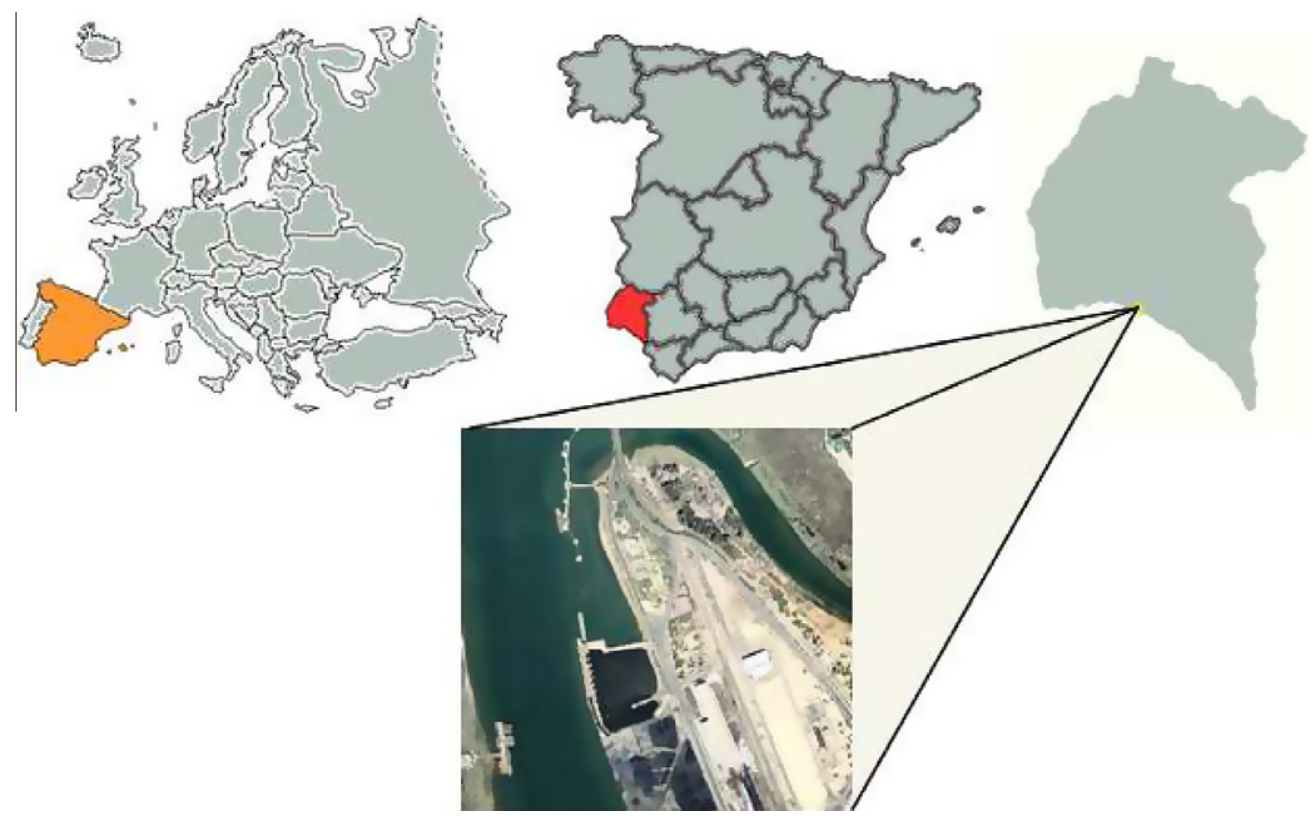

Fig. 1. Study area. The area is found near the city of Huelva, in the mouth of the Tinto and Odiel rivers.

\subsection{Low vegetation}

These areas are interior with sparse and very low vegetation which produces low returns. They have the maximum intensity distribution due to their high reflectivity rate in respect of vegetation cover. Their height is low but greater than in marshland areas.

\subsection{Middle vegetation}

This class is formed by medium sized bushes and located mainly among roads, trees, etc. They have an average level of double or triple returns per pulse. The intensities are also of a mid level varying in relation to whether impact is made on trunk or on leaf. The average height is around one meter.

\subsection{High vegetation}

It is mainly formed by trees and large bush structures. The highest index of multiple returns can be found in this group whilst the average height is found to be in the high area of the overall height distribution.

\subsection{Transport networks}

This class is formed by all infrastructures used to transport people or materials. It is characterized by high intensities and low heights. Furthermore, the majority of pulses only produce one return due to the absence of obstacles.

\subsection{Urban areas}

The most complicated class due to its variability. Intensities and heights vary depending on the material and type of construction. Buildings, landfill and port facilities are found in this class.

\section{Method}

The general form in which the authors evaluate the environmental impact is based on products generated by remote sensing techniques such as LULC maps. In our case, to develop these products, the classification of lidar data is required. With this objective, this study proposes a method based on the application of intelligent techniques on a collection of features previously generated. In Fig. 2, an overall view of the whole classification process can be found which will be described in detail in the following headings.

\subsection{Area selection and pre-processing}

The pixel-oriented strategy obliges us to create a matrix where each element is a pixel. Each pixel represents an area in function of the resolution. The value of resolution must be provided by the user as a method parameter to determine the area within each pixel. In our case, the resolution was fixed at $4 \mathrm{~m}^{2}$. The resolution depends on the density of the points directly: on one hand, two pulses per $\mathrm{m}^{2}$ is not advised for use with bigger resolutions mainly due to lack of sufficient pulses to apply the algorithm; on the other hand, lower resolutions produce noise in smaller classes like roads, which usually are not wider than 3 or $4 \mathrm{~m}$. The resolution chosen implies that the total pixels for classification are 141,376. Apart from the resolution, it is necessary to supply a DTM (Garcia-Gutierrez, Martinez-Alvarez, \& Riquelme-Santos, 2008) to extract the actual heights of the returns.

In addition, the flight must be pre-processed to eliminate distinct types of noise, applying two types of techniques. The first is a correction of intensity (Hofle \& Pfeifer, 2007) in accordance to Eq. (1), where $I$ is the original intensity for a return, $R$ is the distance from the laser source to the furthest return and $R_{S}$ is the actual distance from the source to the return itself. The second technique of pre-processing applies a statistical method of outlier elimination on the $z$ component of the points. Thus, through a filter on the 95th percentile, those points with heights above $17 \mathrm{~m}$ are eliminated. Lastly, a smoothing method is applied based on (Lee, 1980 ) to mitigate the influence of possible outliers that appear undetected with respect to return intensity.

$I\left(R_{s}\right)=I * \frac{R^{2}}{R_{s}^{2}}$.

\subsection{Model generation}

Supervised learning needs previously classified data. For this task, knowledge extracted from the available products in the REDI- 


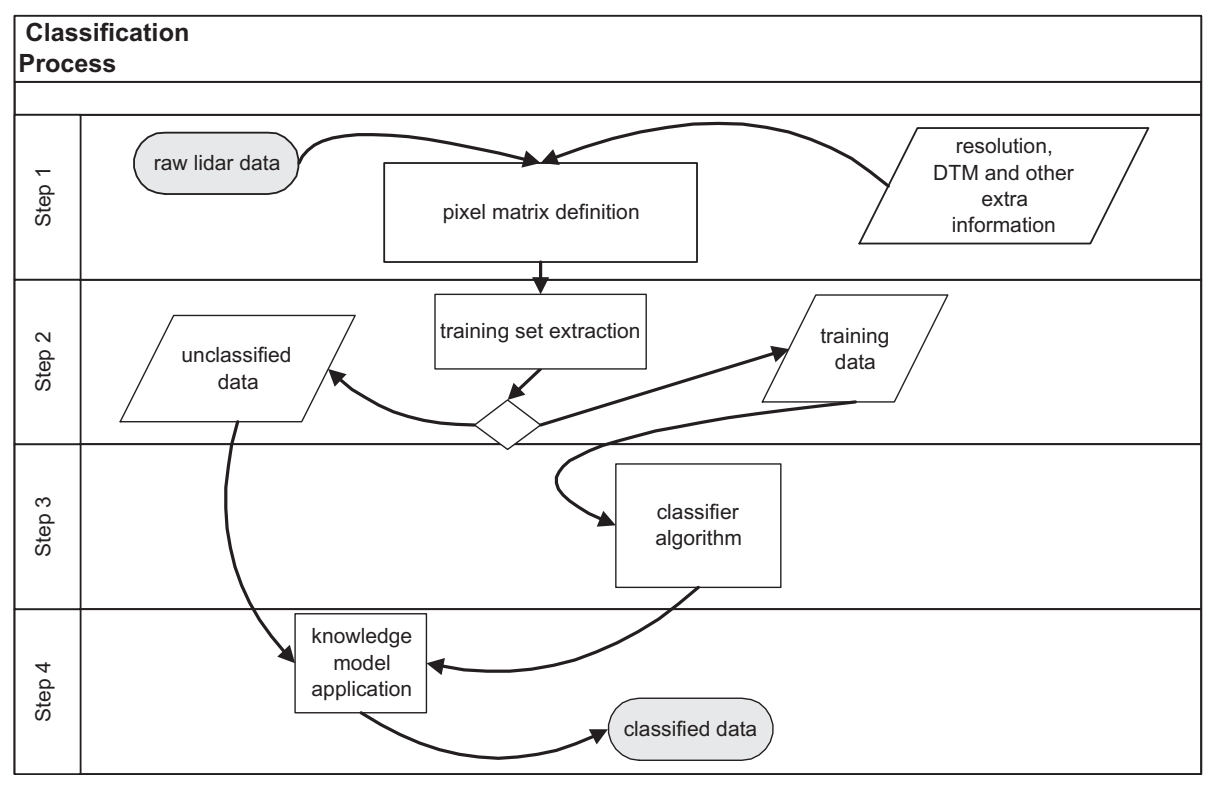

Fig. 2. Classification process.

AM is used to manually classify around 3\% of all data (2168 pixels). Furthermore, to extract the training set, it is necessary to use supporting photographs taken on the same flight as that of lidar data.

Once the resolution is fixed and input data pre-processed, construction of the pixel matrix follows. Each selected pixel is labelled as part of the training set. For each pixel, a set of features based on the intensity, height and pulse distribution is calculated. These features can be classified as intrapixel or interpixel. The intrapixel features are those which are calculated with pulse data found within a pixel, whilst the interpixel features are those which are characterized as defining a relation between each pixel and its eight adjacent neighbours. With these features, characterization of the terrain is attempted, formalizing the visual differences or morphologies of the different classes.

Table 1 contains the 33 different features used in this study. The majority of the features have been extracted from the bibliography (Hudak, Crookston, Evans, Halls, \& Falkowski, 2008) except the following, which are original contributions of this work:

- RZDIFF: Summation of the distances between the first returns and subsequent returns.

- RDIFF: Difference in heights between neighbouring pixels.

- EMP: Number of empty neighbouring pixels.

Once the training set formed by the labelled pixels with their classes is completed, the generation of features proceeds. To carry out this task, original ad hoc software was developed. Before generating the model, a method of attribute selection is applied: CFS (Hall, 1999) that evaluates the worth of a subset of attributes by considering the individual predictive ability of each feature along with the degree of redundancy between them. Subsets of features that are highly correlated with the class while having low intercorrelation are preferred. For our data, the method selected 13 attributes: IMEAN, IMIN, HMEAN, HMIN, HMAX, HCV, SLP, CRR, ISKEW, PCT21, EMP, RDIFF and RZDIFF. As it is possible to observe, the three new features were included in the subset, verifying their importance.

With the selected features already generated, the next phase is the execution of the classification algorithm. Three types of intelligent techniques have been studied to extract the model: vectorsupport machines (SVM) (Cortes \& Vapnik, 1995), artificial neural
Table 1

Thirty-three candidate predictor variables with 10 final selected variables indicated in bold.

\begin{tabular}{lll}
\hline Variable & Description & Type \\
\hline IMIN & Intensity minimum & Intrapixel \\
IMAX & Intensity maximum & Intrapixel \\
IMEAN & Intensity mean & Intrapixel \\
IVAR & Intensity variance & Intrapixel \\
ISTD & Intensity standard deviation & Intrapixel \\
IAAA & Intensity average absolute deviation & Intrapixel \\
IRANGE & Intensity range & Intrapixel \\
HMIN & Height minimum & Intrapixel \\
HMAX & Height maximum & Intrapixel \\
HMEAN & Height mean & Intrapixel \\
HVAR & Height variance & Intrapixel \\
HSTD & Height standard deviation & Intrapixel \\
HAAA & Height average absolute deviation & Intrapixel \\
HRANGE & Height range & Intrapixel \\
IKURT & Intensity Kurtosis & Intrapixel \\
ISKEW & Intensity Skewness & Intrapixel \\
HKURT & Height Kurtosis & Intrapixel \\
HSKEW & Height Skewness & Intrapixel \\
ICV & Intensity coefficient of variation & Intrapixel \\
HCV & Height coefficient of variation & Intrapixel \\
SLP & Slope & Interpixel \\
RDIFF & Relative difference among neighbours & Interpixel \\
RZDIFF & Elevation difference between first and last return & Interpixel \\
PCT1 & Percentage 1st returns & Intrapixel \\
PCT2 & Percentage 2nd returns & Intrapixel \\
PCT3 & Percentage 3rd or later returns & Intrapixel \\
PCT31 & Percentage 3rd returns over 1st returns & Intrapixel \\
PCT21 & Percentage 2nd returns over 1st returns & Intrapixel \\
PCT32 & Percentage 3rd returns over 2nd returns & Intrapixel \\
NOTFIRST & Percentage 2nd or later returns & Intrapixel \\
EMP & Empty plots surrounding & Interpixel \\
TPO & Total number of points & Intrapixel \\
CRR & Canopy relief ratio & Intrapixel \\
\hline
\end{tabular}

networks (ANN) and decision trees (DT) (Friedl \& Brodley, 1997). The following implementations were chosen: in the case of the neural network, a Multilayer Perceptron, a classifier that uses backpropagation to classify instances; for the SVM, the implementation of EL-Manzalawy \& Honavar (2005) was used; for the decision tree definition, the algorithm C4.5 (Quinlan, 1996) was used. The three models were executed in the data mining environment WEKA (Witten \& Frank, 2005). 


\section{Results}

\subsection{Comparison of methods}

To select the technique which is best adapted to our data, a 10fold cross validation was carried out also used to evaluate the classification methods in remote sensing (Tooke, Coops, Goodwin, \& Voogt, 2009). The tests carried out show that the decision trees obtained the best results. In Table $2-4$, the total and partial precisions and the kappa index of agreement (KIA) obtained for the three techniques on the 2168 training pixels are shown. The three techniques obtained high precision when classifying the pixels, but the application of the decision tree produced an improvement of almost $2 \%$ points. So, the decision tree is chosen as the model extraction method. It is important to emphasize that this technique provides a white box model (it explains how decisions are made). The other techniques do not provide an easily understandable model. Bearing in mind that the final user is not an expert in intelligent techniques, greater control of the model would improve satisfying their needs. In addition, the potential of decision trees to indicate which features in the original set are interesting or not and to what extent, which allows automatic selection of attributes, must be underlined.

In order to evaluate the statistical significance of the measured differences in algorithm ranks, a procedure suggested in several works (Demsar, 2006; Garcia \& Herrera, 2008) for robustly comparing classifiers across multiple datasets is used. In this case, there is only one dataset because lidar data has high costs to be obtained. Therefore, the training set is split in five subsets randomly. Then, a 10-fold-cross-validation is made for every subset. At the end, there are 50 measures for every algorithm and then, the procedure is carried out.

The chosen procedure involves the use of the Friedman test to establish the significance of the differences between classifier ranks and, potentially, a post hoc test to compare classifiers to each other. In our case, the goal was to compare the performance of the rival algorithms to that of $\mathrm{C} 4.5$ (control classifier). Pairwise comparisons should not be used when we in fact only test whether a newly proposed method is better than the existing ones. Thus, the Holm procedure was selected as the appropriate post hoc test.

The Friedman test is a non-parametric statistical test for evaluating the differences between more than two related sample means - where the related samples are, in our case, the performances of $k$ classifiers across $n$ target datasets. In our case, we are working with five datasets made by random selections from

Table 2

Summary of the tests on SVM and confusion matrix.

\begin{tabular}{|c|c|c|c|c|c|c|c|}
\hline $\begin{array}{l}\text { User } \\
\text { class } \backslash \text { sample }\end{array}$ & Water & Marsh & $\begin{array}{l}\text { Roads and } \\
\text { railways }\end{array}$ & $\begin{array}{l}\text { Low } \\
\text { veg. }\end{array}$ & $\begin{array}{l}\text { Mid } \\
\text { veg. }\end{array}$ & $\begin{array}{l}\text { High } \\
\text { veg. }\end{array}$ & $\begin{array}{l}\text { Urban } \\
\text { terrain }\end{array}$ \\
\hline Water & 87 & 1 & 0 & 0 & 0 & 0 & 0 \\
\hline Marsh & 2 & 624 & 0 & 0 & 3 & 0 & 0 \\
\hline $\begin{array}{l}\text { Roads and } \\
\text { railways }\end{array}$ & 0 & 1 & 179 & 0 & 2 & 0 & 20 \\
\hline Low veg. & 0 & 0 & 0 & 138 & 1 & 0 & 3 \\
\hline Mid veg. & 0 & 1 & 2 & 0 & 116 & 1 & 14 \\
\hline High veg. & 0 & 0 & 0 & 0 & 1 & 103 & 10 \\
\hline $\begin{array}{l}\text { Urban } \\
\text { terrain }\end{array}$ & 0 & 19 & 5 & 7 & 11 & 5 & 812 \\
\hline $\begin{array}{l}\text { Producer's } \\
\text { accuracy }\end{array}$ & 0.98 & 0.97 & 0.96 & 0.95 & 0.87 & 0.94 & 0.95 \\
\hline $\begin{array}{l}\text { User's } \\
\text { accuracy }\end{array}$ & 0.99 & 0.99 & 0.98 & 0.97 & 0.87 & 0.9 & 0.94 \\
\hline $\begin{array}{l}\text { Total } \\
\text { accuracy }\end{array}$ & 94.97 & & & & & & \\
\hline $\mathrm{KIA}$ & 0.93 & & & & & & \\
\hline
\end{tabular}

Table 3

Summary of the tests on ANN and confusion matrix.

\begin{tabular}{|c|c|c|c|c|c|c|c|}
\hline $\begin{array}{l}\text { User } \\
\text { class } \backslash \text { sample }\end{array}$ & Water & Marsh & $\begin{array}{l}\text { Roads and } \\
\text { railways }\end{array}$ & $\begin{array}{l}\text { Low } \\
\text { veg. }\end{array}$ & $\begin{array}{l}\text { Mid } \\
\text { veg. }\end{array}$ & $\begin{array}{l}\text { High } \\
\text { veg. }\end{array}$ & $\begin{array}{l}\text { Urban } \\
\text { terrain }\end{array}$ \\
\hline Water & 83 & 5 & 0 & 0 & 0 & 0 & 0 \\
\hline Marshland & 3 & 620 & 0 & 0 & 4 & 0 & 2 \\
\hline $\begin{array}{l}\text { Roads and } \\
\text { railways }\end{array}$ & 1 & 1 & 185 & 0 & 9 & 0 & 6 \\
\hline Low veg. & 0 & 1 & 0 & 138 & 0 & 0 & 3 \\
\hline Mid veg. & 0 & 2 & 4 & 0 & 113 & 1 & 14 \\
\hline High veg. & 0 & 0 & 0 & 0 & 2 & 105 & 7 \\
\hline $\begin{array}{l}\text { Urban } \\
\text { terrain }\end{array}$ & 1 & 17 & 7 & 6 & 16 & 12 & 800 \\
\hline $\begin{array}{l}\text { Producer's } \\
\text { accuracy }\end{array}$ & 0.94 & 0.95 & 0.94 & 0.96 & 0.78 & 0.88 & 0.96 \\
\hline $\begin{array}{l}\text { User's } \\
\text { accuracy }\end{array}$ & 0.94 & 0.99 & 0.92 & 0.97 & 0.84 & 0.92 & 0.93 \\
\hline $\begin{array}{l}\text { Total } \\
\text { accuracy }\end{array}$ & 94.28 & & & & & & \\
\hline KIA & 0.92 & & & & & & \\
\hline
\end{tabular}

Table 4

Summary of the tests on DT and confusion matrix.

\begin{tabular}{|c|c|c|c|c|c|c|c|}
\hline $\begin{array}{l}\text { User } \\
\text { class } \backslash \text { sample }\end{array}$ & Water & Marsh & $\begin{array}{l}\text { Roads and } \\
\text { railways }\end{array}$ & $\begin{array}{l}\text { Low } \\
\text { veg. }\end{array}$ & $\begin{array}{l}\text { Mid } \\
\text { veg. }\end{array}$ & $\begin{array}{l}\text { High } \\
\text { veg. }\end{array}$ & $\begin{array}{l}\text { Urban } \\
\text { terrain }\end{array}$ \\
\hline Water & 88 & 0 & 0 & 0 & 0 & 0 & 0 \\
\hline Marshland & 0 & 624 & 0 & 0 & 0 & 0 & 5 \\
\hline $\begin{array}{l}\text { Roads and } \\
\text { railways }\end{array}$ & 0 & 1 & 190 & 0 & 4 & 0 & 7 \\
\hline Low veg. & 0 & 0 & 0 & 134 & 0 & 0 & 8 \\
\hline Middle veg. & 0 & 1 & 3 & 0 & 120 & 2 & 8 \\
\hline High veg. & 0 & 0 & 0 & 0 & 0 & 105 & 9 \\
\hline $\begin{array}{l}\text { Urban } \\
\text { terrain }\end{array}$ & 0 & 6 & 7 & 1 & 11 & 4 & 830 \\
\hline $\begin{array}{l}\text { Producer's } \\
\text { accuracy }\end{array}$ & 1.0 & 0.99 & 0.95 & 0.99 & 0.88 & 0.95 & 0.96 \\
\hline $\begin{array}{l}\text { User's } \\
\text { accuracy }\end{array}$ & 1.0 & 0.99 & 0.94 & 0.94 & 0.9 & 0.92 & 0.97 \\
\hline $\begin{array}{l}\text { Total } \\
\text { accuracy }\end{array}$ & 96.45 & & & & & & \\
\hline KIA & 0.95 & & & & & & \\
\hline
\end{tabular}

the original set. The null hypothesis being tested is that all classifiers perform the same and any observed differences are merely random. This is equivalent to testing whether the measured average ranks $r_{j}$ are significantly different from the expected mean rank. The statistic used in the Friedman test can be seen in Eq. (2).

$\left.X_{F}^{2}=\frac{12 n}{k(k+1)} \sum_{j} r_{j}^{2}-\frac{k(k+1)^{2}}{4}\right)$.

Average ranks provide a fair comparison of the algorithms, revealing that, on average, $C 4.5$ ranks first. Given the measured average ranks, the Friedman test checks whether the average ranks are significantly different from the mean rank $r=2.0$ expected under the null hypothesis. Leaning on a statistical package (MATLAB), $p$-value for the Friedman test has resulted on a value of $2.923 e-10$ so the null hypothesis is rejected, having found that the measured average ranks are significantly different (at $\alpha=0.05$ ). Provided that the Friedman test rejects the null hypothesis, we can proceed with a post hoc test that evaluates the relative performance of the studied algorithms against a control algorithm $r_{0}$ (in our case, C4.5). One such test is the Holm step-down procedure that tests hypotheses sequentially ordered by their significance. The $z$-statistic comparing the $i$ th classifier against the control one can be seen in Eq. (3). 
$z=\frac{\left(r_{i}-r_{0}\right)}{\sqrt{\frac{k(k+1)}{6 n}}}$.

With the Holm post hoc test, we can decide whether C4.5 is significantly better than its rival algorithms. If $p_{i}$ is below $\alpha /(k-i)$, the corresponding hypothesis is rejected and we proceed to comparing $p_{i}+1$ with $\alpha /(k-i-1)$. As soon as a certain null hypothesis cannot be rejected, all the remaining hypotheses are retained as well. In our case, the Holm procedure rejects all hypotheses as can be seen in Table 5 , since the corresponding $p$-values are smaller than the adjusted $\alpha$ values in all cases. The analysis, thus, reveals that at $\alpha=0.05$, the performances of all rival algorithms (SVM and Multilayer Perceptron) are significantly worse than that of C4.5.

\subsection{Model precision}

As was pointed out previously, to construct the decision tree (see Fig. 3) 3\% of the available pixels were used. The subsequent

Table 5

Holm test summing up with C4.5 (averaged rank $=1.33$ ).

\begin{tabular}{llllll}
\hline$i$ & Test & Averaged rank $\left(r_{i}\right)$ & $p$-Value of $z$ & $\alpha /(k-i)$ & Comment \\
\hline 1 & ANN & 2.63 & 0.00001 & 0.0253 & Reject Ho \\
2 & SVM & 2.04 & 0.0017 & 0.0500 & Reject Ho \\
\hline
\end{tabular}

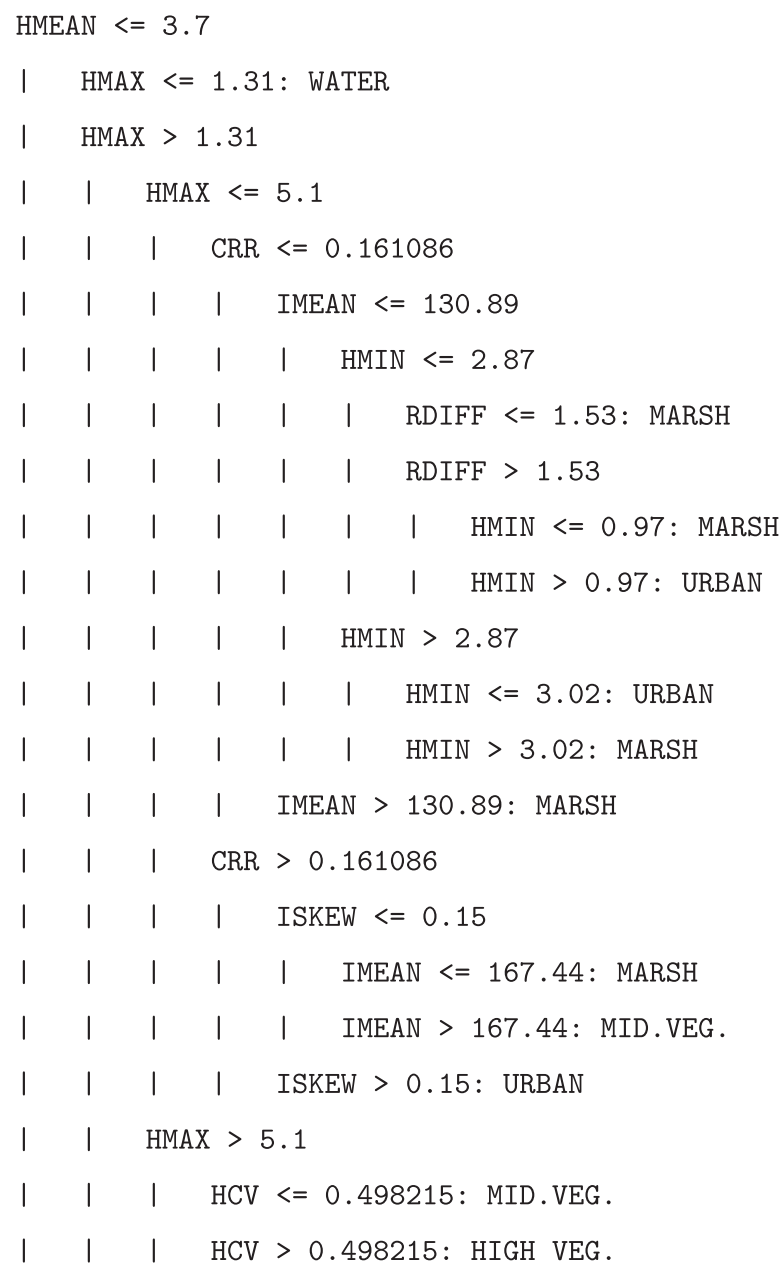

HMEAN $>3.7$

Fig. 3. A part of the model for the study zone. classification of the remaining points produces the results in Fig. 4 which will be commented on in the following section. To estimate the error, a stratified test with 187 points was carried out. The data of the test were randomly selected from the initial unclassified set and the classes to which they pertained were evaluated. In a stratified test, the proportion among the classes was maintained in respect to the original proportion of the training data. In Table 6 , it is possible to observe the results of the test through the confusion matrix, producer and user's accuracies, and the kappa estimator of the tree obtained in the training phase.

The C4.5 algorithm gives rise to another selection of attributes. Apart from the subset of 13 features generated by the CFS method, 10 final features remain. Within them, it is important to emphasize that two of the new proposed features appear, RDIFF and RZDIFF. The level of the node in which a feature is used gives the importance of that feature for the algorithm, more so, the closer to the root of the tree it is. In Table 7, the distances of each selected feature in respect to the root of the tree can be viewed. Note that the new features, RZDIFF and RDIFF, are used in level 2 and level 6 nodes, respectively.

The final result of the classification is a LULC map at a resolution of $4 \mathrm{~m}$ and an average precision of $85 \%$. In Fig. 4, a comparison of the original orthophoto, the training set and the final result of the classification is shown.

\section{Discussion}

In terms of the results of the classification method (Table 6), it must be taken into account that although the riparian areas present great difficulties for classification, the results show a great overall precision. According to the latest studies (Shao \& Wu, 2008), the general precisions of LULC maps developed for many organizations do not exceed $85 \%$ despite this being the standard for considering a LULC map a useful product. The proposed method demonstrates achieving this level generally and even exceeding it amply for specific classes. Analyzing the results in more depth, we see that separability between classes through our lidar data is proved and the method can be applied without the need of other auxiliary sources.

Regarding the analysis of each class, it can be observed that the best results coincide with the submerged areas, roads and marshlands with precisions exceeding $90 \%$. The worst results are those that provide classification of middle vegetation and urban areas with values around $72 \%$ of the overall precision. The latter is due to medium vegetation being an intermediate class that can confuse the algorithm as low vegetation and the urban class is a complicated class with many subtypes. Some of them can share characteristics of other classes, which leads to a greater probability of failure.

Although good results have been obtained, some areas with a relative high level of errors can be detected in the final result, mainly in the areas of the harbor. This is inherent in pixel-oriented approaches which attempt to classify without considering the context of each pixel. The same problem appears in some roofless constructions. In the case of the port area, the type of terrain that supports it posses a reflective response very similar to other terrain nearby which causes the algorithm to fail. This problem must be addressed in future works. Furthermore, some areas show severe levels of noise probably caused by outliers in intensity. The pasture areas are an example of this behaviour where pixels with equal height distribution and density give place to two distinct classes. Bearing in mind that lidar only works with heights, densities and intensities, it is concluded that the error must be in the intensity. Therefore, work must continue in the pre-processing of the intensity. 


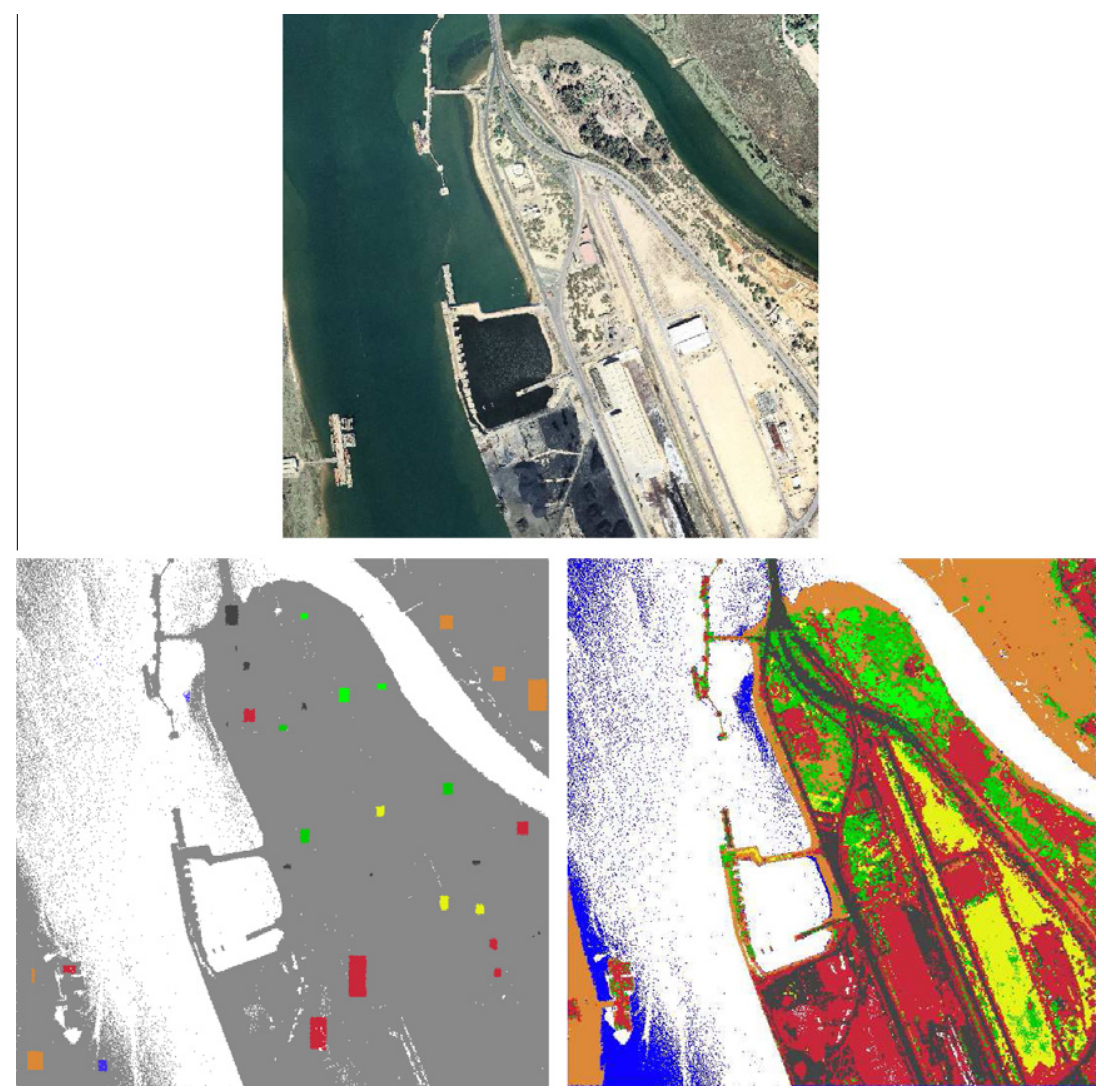

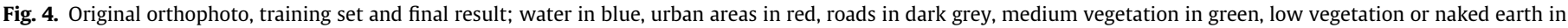

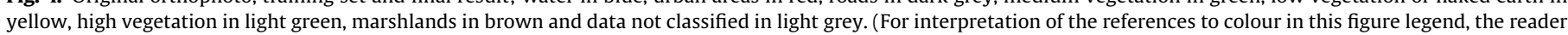
is referred to the web version of this article.)

Table 6

Summary of the final test set and confusion matrix.

\begin{tabular}{|c|c|c|c|c|c|c|c|}
\hline $\begin{array}{l}\text { User } \\
\text { class } \backslash \text { sample }\end{array}$ & Water & Marsh & $\begin{array}{l}\text { Roads and } \\
\text { railways }\end{array}$ & $\begin{array}{l}\text { Low } \\
\text { veg. }\end{array}$ & $\begin{array}{l}\text { Mid } \\
\text { veg. }\end{array}$ & $\begin{array}{l}\text { High } \\
\text { veg. }\end{array}$ & $\begin{array}{l}\text { Urban } \\
\text { terrain }\end{array}$ \\
\hline Water & 32 & 0 & 0 & 0 & 0 & 0 & 0 \\
\hline Marshland & 0 & 30 & 0 & 0 & 0 & 0 & 4 \\
\hline $\begin{array}{l}\text { Roads and } \\
\text { railways }\end{array}$ & 0 & 0 & 28 & 0 & 0 & 0 & 7 \\
\hline Low veg. & 0 & 0 & 0 & 14 & 0 & 0 & 1 \\
\hline Mid veg. & 0 & 0 & 0 & 2 & 12 & 0 & 3 \\
\hline High veg. & 0 & 0 & 0 & 0 & 0 & 3 & 0 \\
\hline $\begin{array}{l}\text { Urban } \\
\text { terrain }\end{array}$ & 0 & 0 & 2 & 4 & 5 & 1 & 38 \\
\hline $\begin{array}{l}\text { Producer's } \\
\text { accuracy }\end{array}$ & 1.0 & 1.0 & 0.93 & 0.7 & 0.71 & 0.75 & 0.73 \\
\hline $\begin{array}{l}\text { User's } \\
\text { accuracy }\end{array}$ & 1.0 & 0.88 & 0.8 & 0.93 & 0.71 & 1.0 & 0.76 \\
\hline $\begin{array}{l}\text { Total } \\
\text { accuracy }\end{array}$ & 0.85 & & & & & & \\
\hline KIA & 0.81 & & & & & & \\
\hline
\end{tabular}

Apart from the map generated (Fig. 4), it is relatively simple to analyze the condition of the study area. As can be observed, the urban zone (in red) extends practically over the whole area. The roads segment the central area in such a way that the little vegetation that remains appears isolated by roads or railways. Only areas prone to flooding remain as original marshlands, whilst high vegetation appears to extend through old abandoned urban areas. The dry pastures occupy the central area but surrounded by roads and urban areas, which could provoke its disappearance in the near future. The generated map reveals that the area which contains major roads is found to be subjected to great human impact, whilst
Table 7

Ten final variables selected by C4.5 decision tree and their distance to the root.

\begin{tabular}{ll}
\hline Attribute & Tree level \\
\hline HMEAN & 0 \\
HMAX & 1 \\
HMIN & 2 \\
RZDIFF & 2 \\
CRR & 3 \\
HCV & 3 \\
IMEAN & 3 \\
ISKEW & 4 \\
IMIN & 5 \\
RDIFF & 6 \\
\hline
\end{tabular}

the bulk of peripheral areas maintain their original land, except for small auxiliary constructions. In this way, the theory (Goetz et al., 2009; Svancara et al., 2009) that roads are a key parameter to evaluate exposed risk to any type of original terrain, protected or not, is confirmed.

\section{Conclusions and future work}

Public investments destined for conservation of the environment can be seen to reduce in the context of economic crisis. The low level of automation to apply policies and environment protection methodologies causes implementation costs to be higher in many cases. It is therefore necessary, to apply new techniques that reduce such costs and improve the quality of the final product to increase productivity. 
In this work, an approach based on lidar data and intelligent techniques to classify land uses and land cover of Mediterranean riparian areas was analyzed. The objective is to evaluate environmental quality of the land in an area close to natural surroundings in the south of Spain. The developed method is based on a pixeloriented focus which classifies raw data in seven different classes. From lidar data, a series of features are calculated (some of them are original in this work) which are associated with each pixel. Thereafter, an attribute selection method is applied to reduce the set of variables to consider. Lastly, the extraction algorithm of the classification model is applied. The tests carried out selected the algorithm C4.5, which generates a decision tree, as the model. Therefore, it has been demonstrated that different types of terrain can be characterized using intelligent techniques in a multi-staged process using lidar data.

With the application of intelligent techniques on lidar, it achieves: first, to reduce development time of products required in environmental tasks due to an increase in automation; and second, reuse lidar data which is traditionally used to develop DTM's, and as has been seen, can serve to develop LULC maps. The method does not make use of additional data such as images and the precision shown is adequate to treat areas extremely complicated to classify whilst maintaining a very low computational cost.

In relation to future works, two problems arise. The first is the need to integrate a method to work with temporal series of lidar flights with the objective of giving capacity to the system to monitor the distinct study areas. The second is the improvement of the classification method itself, as some problems have already been detected. Some are inherent in pixel-oriented approaches such as the detection of partial structures. In the future, it would be very interesting to apply a prior phase in which at low addition to the computational cost, an object-oriented segmentation and classification could be carried out to extract the most difficult structures to classify. Furthermore, it has been observed that the detection of outliers in the lidar return intensity is a task to be improved, since it generates the majority of classification errors.

\section{Acknowledgements}

The authors thank the Regional Ministry of Andalusia for all the support received in the development of this work and especially, to thank Irene Carpintero, Juan José Vales, Daniel Laguna and Michael Grainge for all the time they invested that allowed this work to be completed.

\section{References}

Antonarakis, A., Richards, K., \& Brasington, J. (2008). Object-based land covers classification using airborne lidar. Remote Sensing of Environment, 112, 2988-2998.

Arroyo, L. A., Pascual, C., \& Manzanera, J. A. (2008). Fire models and methods to map fuel types: The role of remote sensing. Forest Ecology and Management, 256, 1239-1252.

Bork, E. W., \& Su, J. G. (2007). Integrating lidar data and multispectral imagery for enhanced classification of rangeland vegetation: A meta analysis. Remote Sensing of Environment, 111, 11-24.

Brzank, A., Heipke, C., Goepfert, J., \& Segel, U. (2008). Aspects of generating precise digital terrain models in the wadden sea form lidar-water classification and structure line extraction. ISPRS Journal of Photogrammetry and Remote Sensing, $63,510-528$.

Chen, Q. (2007). Airborne lidar data processing and information extraction. Photogammetry Engineering and Remote Sensing, 2(73), 109-112.

Chen, Y., Su, W., Li, J., \& Sun, Z. (2009). Hierarchical object oriented classification using very high resolution imagery and lidar data over urban areas. Advances in Space Research, 43(7), 1101-1110.

Chust, G., Galparsoro, I., Franco, A. B. J., \& Uriarte, A. (2008). Coastal and estuarine habitat mapping, using lidar height and intensity and multi-spectral imagery. Estuarine, Coastal and Shelf Science, 78(4), 633-643.

Cortes, C., \& Vapnik, V. (1995). Support-vector networks. Machine Learning, 273-297.
Dalponte, M., Bruzzone, L., \& Gianelle, D. (2008). Fusion of hyperspectral and lidar remote sensing data for classification of complex forest areas. IEEE Transaction on Geoscience and Remote Sensing, 46(5), 1416-1427.

Demsar, J. (2006). Statistical comparisons of classifiers over multiple data sets. Journal of Machine Learning Research, 7, 1-30.

Donoghue, D. N., Watt, P. J., Cox, N. J., \& Wilson, J. (2007). Remote sensing of species mixtures in conifer plantations using lidar height and intensity data. Remote Sensing of Environment, 110, 110-509.

Dorigo, W. A., Zurita-Milla, R., de Wit, A. J. W., Brazile, J., Singh, R., \& Schaepman, M E. (2007). A review on reflective remote sensing and data assimilation techniques for enhanced agroecosystem modeling. International Journal of Applied Earth Observation and Geoinformation, 9, 165-193.

EL-Manzalawy, Y., \& Honavar, V. (2005). WLSVM: Integrating LibSVM into Weka environment. Software available at URL <http://www.cs.iastate.edu/ yasser/ wlsvm>.

Evans, J. S., \& Hudak, A. T. (2007). A multiscale curvature algorithm for classifying discrete return lidar in forested environments. IEEE Transactions on Geoscience and Remote Sensing, 45(4), 1029-1038.

Fraser, R., Olthof, I., \& Pouliot, D. (2009). Monitoring land cover change and ecological integrity in Canada's National Parks. Remote Sensing of Environment 113, 1397-1409.

Friedl, M. A., \& Brodley, C. E. (1997). Decision tree classification of land cover from remotely sensed data. Remote Sensing of Environment, 61, 399-409.

Gamanya, R., Maeyer, P. D., \& Dapper, M. D. (2007). An automated satellite image classification design using object-oriented segmentation algorithms: A move towards standardization. Expert Systems with Applications, 32, 616-624.

Gamanya, R., Maeyer, P. D., \& Dapper, M. D. (2009). Object-oriented change detection for the city of Harare, Zimbabwe. Expert Systems with Applications, 36 571-588.

Garcia-Gutierrez, J., Martinez-Alvarez, F., \& Riquelme-Santos, J. C. (2008). Remote mining: From clustering to dtm. In Proceedings of the ISPRS workshop SilviLaser.

Garcia, S., \& Herrera, F. (2008). An extension on statistical comparisons of classifiers over multiple data sets for all pairwise comparisons. Journal of Machine Learning Research, 9, 2677-2694.

Gill, S., Handley, J. F., Ennos, A. R., Pauleit, S., Theuray, N., \& Lindley, S. (2008). Characterising the urban environment of UK cities and towns: A template for landscape planning. Landscape and Urban Planning, 87, 210-222.

Goetz, S., Jantz, P., \& Jantz, C. A. (2009). Connectivity of core habitat in the Northeastern United States: Parks and protected areas in a landscape context Remote Sensing of Environment, 113, 1421-1429.

Goetz, S., Steinberg, D., Dubayah, R., \& Blair, B. (2007). Laser remote sensing of canopy habitat heterogeneity as a predictor of bird species richness in an eastern temperature forest, USA. Remote Sensing of Environment, 108, 254-263.

Hall, M. A. (1999). Correlation-based feature selection for machine learning. Tech. rep., Hamilton, New Zealand.

Hofle, B., \& Pfeifer, N. (2007). Correction of laser scanning intensity data: Data and model-driven approaches. ISPRS Journal of Photogrammetry and Remote Sensing, 62(6), 415-433.

Hudak, A. T., Crookston, N. L., Evans, J. S., Halls, D. E., \& Falkowski, M. J. (2008). Nearest neighbor imputation of species-level, plot-scale forest structure attributes from lidar data. Remote Sensing of Environment, 112, 2232-2245.

Jensen, J. L. R., Humes, K. S., Vierling, L. A., \& Hudak, A. T. (2008). Discrete return lidar-based prediction of leaf area index in two conifer forests. Remote Sensing of Environment, 112, 2988-2998.

Jones, D. A., Hansen, A. J., Bly, K., Doherty, K., Verschuyl, J. P., Paugh, J. I., et al. (2009). Monitoring land use and cover around parks: A conceptual approach. Remote Sensing of Environment, 113, 1346-1356.

Kennedy, R. E., Townsend, P. A., Gross, J. E., Cohen, W. B., Bolstad, P., Wang, Y., et al (2009). Remote sensing change detection tools for natural resource managers: Understanding concepts and tradeoffs in the design of landscape monitoring projects. Remote Sensing of Environment, 113, 1382-1396.

Koetz, B., Morsdorf, F., van der Linden, S., Curt, T., \& Allgower, B. (2008). Multi-source land cover classification for forest fire management based on imaging spectrometry and lidar data. Forest Ecology and Management, 256, 263-271.

Kokaly, R. F., Rockwell, B. W., Haire, S. L., \& King, T. V. V. (2007). Characterization of post-fire surface cover, soils, and burn severity at the cerro grande fire, new mexico, using hyperspectral and multispectral remote sensing. Remote Sensing of Environment, 106, 305-325.

Lee, J. S. (1980). Digital image and noise filtering by use of local statistics. IEEE Transactions on Pattern Analysis and Machine Intelligence, 2, 165-168.

Pascual, C., Garcia-Abril, A., Garcia-Montero, L., Martin-Fernandez, S., \& Cohen, W. (2008). Object-based semi-automatic approach for forest structure characterization using lidar data in heterogeneus pinus sylvestris stands. Forest Ecology and Management, 255, 3677-3685.

Pignatti, S., Cavalli, R. M., Cuomo, V., Fusilli, L., Pascucci, S., Poscolieri, M., et al. (2009). Evaluating hyperion capability for land cover mapping in a fragmented ecosystem: Pollino National Park, Italy. Remote Sensing of Environment, 113, 622-634.

Quinlan, J. R. (1996). Improved use of continuous attributes in c4.5. Journal of Artificial Intelligence Research, 4, 77-90.

Schneider, J., Grosse, G., \& Wagner, D. (2009). Land cover classification of tundra environments in the arctic lena delta based on landsat 7 etm+ data and its application for upscaling of methane emissions. Remote Sensing of Environment 113, 380-391. 
Schubert, J. E., Sanders, B. F., Smith, M. J., \& Wright, N. G. (2008). Unstructured mesh generation and landcover-based resistance for hydrodynamic modeling of urban flooding. Advances in Water Resources, 31, 1603-1621.

Shao, G., \& Wu, J. (2008). On the accuracy of landscape pattern analysis using remote sensing data. Landscape Ecology, 23, 505-511.

Sithole, G., \& Vosselman, G. (2003). Comparison of filtering algorithms. Internationa Archives of Photogrammetry, Remote Sensing and Spatial Information Sciences, 34 $71-78$

Stow, D., Hamada, Y., Coulter, L., \& Anguelova, Z. (2008). Monitoring shrubland habitat changes through object-based change identification with airborne multispectral imagery. Remote Sensing of Environment, 112, 1051-1061.

Svancara, L. K., Scott, J. M., Loveland, T. R., \& Pidgorna, A. B. (2009). Assessing the landscape context and conversion risk of protected areas using satellite data products. Remote Sensing of Environment, 113, 1357-1369.

Thessler, S., Sesnie, S., Bendana, Z. S. R., Ruokolainen, K., Tomppo, E., \& Finegan, B. (2008). Using $k$-nn and discriminant analyses to classify rain forest types in a landsat tm image over northern costa rica. Remote Sensing of Environment, 112, 2485-2494.

Tooke, T. R., Coops, N. C., Goodwin, N., \& Voogt, J. A. (2009). Extracting urban vegetation characteristics using spectral mixture analysis and decision tree classifications. Remote Sensing of Environment, 113, 398-407.

Townsend, P. A., Lookingbill, T. R., Kingdon, C. C., \& Gardner, R. H. (2009). Spatial pattern analysis for monitoring protected areas. Remote Sensing of Environment, $113,1410-1420$

Wang, Y., Mitchell, B. R., Nugranad-Marzilli, J., Bonynge, G., Zhou, Y., \& Shriver, G. (2009). Remote sensing of land-cover change and landscape context of the national parks: A case study of the northeast temperate network. Remote Sensing of Environment, 113, 1453-1461.

Witten, H., \& Frank, E. (2005). Data mining: Practical machine learning tools and techniques. Morgan Kaufmann Publishers. 